\title{
Nutrient fluxes from land to ocean: the importance of groundwater discharge and continental shelf \\ waters
}

\author{
HyUNG-Mi $\mathrm{CHO}^{1 *}$ AND GUEBUEM KIM ${ }^{1}$
}

${ }^{1}$ School of Earth and Environmental Sciences/RIO, Seoul

National University, Seoul, South Korea

(*correspondense: hm0410@snu.ac.kr)

Fluxes of nutrients to the ocean have large impacts on biological production, carbon cycles, and deoxygenation in the ocean. While global nutrient fluxes via surface runoffs are quite well known, those through submarine groundwater discharge (SGD) are poorly understood. However, the fluxes of nutrients through SGD often exceed riverine inputs in different local and regional scale settings. In this study, our fisrt approximation by combining a global compilation of nutrient concentrations in groundwater and the SGD-derived ${ }^{228} \mathrm{Ra}$ fluxes shows that the fluxes of dissolved inorganic nitrogen (DIN), phosphorus (DIP), and silicon (DSi) to the ocean via total SGD could be approximately 1.4-, 1.6-, and 0.7 -fold of the river fluxes to the global ocean. In addition, continental shelf waters can deliver significant amounts of nutrients to the ocean as the shelf water receives large inputs of nutrients from rivers, groundwater, and the atmosphere. The cross-shelf fluxes of nutrients were estimated in February 2017 by using ${ }^{228} \mathrm{Ra}$ as a tracer in the Yellow Sea and the East China Sea regions connected to the northwest Pacific Ocean. The results show that the cross-shelf fluxes of dissolved $\mathrm{N}$ amounts to approximately $30-40 \%$ of atmospheric depositional fluxes while $\mathrm{P}$ is 2 orders of magnitude greater than the fluxes. Our study implies that subterranean estuaries and coastal margins play an important role on supplying nutrients to ocean from land. 